\title{
Experimenten in de civiele rechtspraak: over integrale kwaliteit en management van verwachtingen
}

\author{
Kim van der Kraats*
}

\begin{abstract}
1 Inleiding
In de civiele rechtspraak vindt momenteel een aantal experimenten plaats. Het gaat onder andere om de Rotterdamse Regelrechter bij de Rechtbank Rotterdam en de Wijkrechter bij de Rechtbank Den Haag. ${ }^{1}$ Op 1 juli 2019 start de Overijsselse Overlegrechter bij de Rechtbank Overijssel. ${ }^{2}$ Deze drie experimenten zijn grotendeels gebaseerd op de inmiddels afgeronde pilot van de Spreekuurrechter bij de Rechtbank NoordNederland. Ze vinden hun wettelijke basis in art. $96 \mathrm{Rv}$, op grond waarvan partijen - als zij daar (na het ontstaan van het geschil) beide mee instemmen - de kantonrechter van hun keuze om een beslissing kunnen vragen in alle zaken die slechts rechtsgevolgen betreffen die ter vrije bepaling van partijen staan en waarbij de kantonrechter de procesvoering bepaalt. ${ }^{3}$

Met deze experimenten wordt beoogd de civiele procedure voor natuurlijke personen sneller, goedkoper, eenvoudiger, laagdrempeliger en ook meer probleemoplossend te maken.

In dit artikel wordt nagegaan in hoeverre de experimenten bijdragen aan de kwaliteit van de civiele procedure. Daartoe worden in paragraaf 2 het oogmerk, de doelgroep en het type zaken van de verschillende experimenten geschetst. In paragraaf 3 wordt een kwaliteitskader gegeven en uiteengezet op welke aspecten van kwaliteit de experimenten inzetten. In paragraaf 4 tot en met 7 wordt achtereenvolgens besproken op welke wijze de experimenten beogen bij te dragen aan snelheid, lagere kosten, laagdrempeligheid, eenvoud en probleemoplossing en de gevolgen hiervan voor de integrale kwaliteit. Afgesloten wordt met een conclusie (par. 8).
\end{abstract}

Mr. dr. K.G.F. van der Kraats is rechter en teamvoorzitter handel en kanton in de Rechtbank Overijssel.

1. Ik heb eerder een artikel geschreven over deze experimenten. Dat richtte zich op de vraag wat de Rechtspraak en de minister hiermee beogen, of dat hetzelfde is, en of dat realistisch is. Zie K.G.F. van der Kraats, 'Experimenten in de civiele rechtspraak: een oplossing voor welk probleem?', Justitiële verkenningen 2019, afl. 1, p. 82-96.

2. Hierbij ben ik als teamvoorzitter in Overijssel zelf betrokken. Om die reden en omdat de Overlegrechter ten tijde van het schrijven van dit artikel nog niet is gestart, wordt aan de Overlegrechter in dit artikel minder aandacht besteed.

3. Ik richt mij dus niet op de Experimenteerwet en experimenten die hun grondslag vinden in die wet.

\section{Oogmerk, doelgroep en type zaken}

Het experiment van de Spreekuurrechter is in mei 2016 bij de Rechtbank Noord-Nederland begonnen en kende een looptijd van twee jaar. ${ }^{4}$ Met de Spreekuurrechter werd beoogd een laagdrempelige, snelle en goedkope vorm van civiele rechtspraak te creëren. ${ }^{5}$ Dit oogmerk stemt overeen met dat van de opvolgers van de Spreekuurrechter; de Regelrechter, de Wijkrechter en de Overlegrechter maken snel, goedkoop en eenvoudig ook tot hun kernwoorden. ${ }^{6} \mathrm{Zij}$ voegen daar evenwel nog aan toe het kernwoord probleemoplossend. ${ }^{7}$

De experimenten beogen 'een laagdrempelige procedure te bieden voor de particulier' en richten zich op rechtzoekenden voor wie de reguliere rechtsgang minder toegankelijk is, omdat procederen voor hen ingewikkeld is, een advocaat of andere gemachtigde nodig is, of procederen kostbaar is. ${ }^{8}{ }^{8} \mathrm{Zo}$ bestaat bij de Regelrechter de indruk dat 'relatief vaak' geschillen in de samenleving onopgelost blijven 'omdat de drempel om die geschillen aan de rechter voor te leggen te hoog is." Ook de Wijkrechter richt zich op zaken die de rechter anders niet bereiken. ${ }^{10}$ Voor de Overlegrechter is dat niet anders. Bij de Spreekuurrechter werd in de evaluatie dan ook onderzocht of zaken in het kader van het experiment waren voorgelegd die niet aan de reguliere rechter zouden zijn voorgelegd. ${ }^{11}$

De experimenten zijn dus bedoeld voor mensen met een smalle beurs, die geen kennis dragen van het (proces)recht en

4. Zie www.rechtspraak.nl/SiteCollectionDocuments/research-memoranda -2018-04.pdf.

5. T. Lennaerts, 'De Spreekuurrechter', NJB 2016/596, p. 802 en 806.

6. W.J.J. Wetzels, 'Nieuw leven voor de procedure ex artikel $96 \mathrm{Rv}$ in de pilot van de Rotterdamse Regelrechter', TAP 2019 (60), afl. 2, p. 9 (hierna: Wetzels 2019a); J. Luiten, 'Maatschappelijk effectieve rechtspraak: de Haagse Wijkrechter en de Rotterdamse Regelrechter', TvPP 2018, afl. 5, p. 138.

7. Wetzels 2019a, p. 9; W. Wetzels, 'De pilot van de Rotterdamse Regelrechter', Justitiële verkenningen, afl. 1, p. 46 (hierna: Wetzels 2019b); K. Pijnappels, 'Proef Haagse Wijkrechter uitgebreid naar regio', Advocatenblad 2019, afl. 3, p. 10.

8. Wetzels 2019a, p. 9; 2019b, p. 43-44.

9. Wetzels 2019b, p. 41.

10. Luiten 2018, p. 137.

11. Dit bleek in ongeveer de helft van de zaken (voornamelijk de burenzaken) het geval: M. Hertogh, M. Batting, C. Boxum, N. Struiksma \& C. Veen, 'Zegt u het eens, wat wilt u van de rechter?' Evaluatie van pilot de Spreekuurrechter (Research Memoranda, nr. 4), Den Haag: Raad voor de rechtspraak 2018, p. 93. 
die kennis moeilijk kunnen verwerven, en daardoor niet of moeilijk hun recht kunnen halen. Het zal dus gaan om natuurlijke personen. Die focus blijkt ook uit het griffierecht dat de Regelrechter en de Overlegrechter hanteren, namelijk een lager griffierecht dan het gebruikelijke als een natuurlijk persoon hierbij partij is (zie ook par. 5). Ondanks die focus beperken de experimenten zich niet tot natuurlijke personen die zonder gemachtigde procederen. Ook bedrijven en gemachtigden kunnen zaken aanbrengen. ${ }^{12}$ Alleen bij de Spreekuurrechter is het aantal mogelijke aanbrengers beperkt; enkel het Juridisch Loket, DAS Nederlandse Rechtsbijstand Verzekeringsmaatschappij N.V., de Stichting Univé Rechtshulp, de Stichting Achmea Rechtsbijstand en Anker Rechtshulp B.V. konden zaken aanbrengen. ${ }^{13}$ Dit riep de nodige kritiek op, aangezien bepaalde partijen werden bevoordeeld doordat zij zaken konden aanbrengen en andere niet. Bij de Overlegrechter kunnen niet alleen partijen zelf of advocaten of gemachtigden zaken aanmelden, ook mediators en buurtbemiddelaars krijgen de mogelijkheid om zaken aan te melden. Bij de Spreekuurrechter was immers gebleken dat dit mogelijk in een behoefte zou kunnen voorzien. ${ }^{14}$

Bij de meeste experimenten kan een breed aanbod van zaken worden aangemeld. ${ }^{15}$ Alleen de Wijkrechter heeft zich beperkt tot overlastzaken, burengeschillen, gebreken in huurwoningen en $\mathrm{VvE}$-geschillen. ${ }^{16}$ Wel staat het de rechtbanken vrij om te beoordelen of de zaak zich leent voor behandeling in het kader van het experiment. ${ }^{17}$ De zaken lenen zich daarvoor als de zaak 'vers' is, 'niet gejuridiseerd' is en eenvoudig (overzichtelijke rechtsvraag) of klein is (geen 'vuistdik' dossier). ${ }^{18}$

Oogmerk van de experimenten is dus het realiseren van een snelle, goedkope, laagdrempelige/eenvoudige en probleemoplossende procedure voor mensen met een smalle beurs, die geen kennis dragen van het (proces)recht en die kennis moeilijk kunnen verwerven, en bijgevolg niet of moeilijk hun recht kunnen halen. In dat licht valt het ten eerste op dat de experimenten niet worden beperkt tot zaken tussen natuurlijke personen of waarbij ten minste één natuurlijke persoon betrokken is, maar ook worden opengesteld voor bedrijven (waaronder eenmanszaken). Daardoor wordt de focus met betrekking tot de doelgroep verbreed ten opzichte van het hiervoor genoemde oogmerk van de experimenten om mensen met een smalle beurs, die geen kennis dragen van het

12. Luiten 2018, p. 138.

13. Procesreglement, onder 3, www.rechtspraak.nl/SiteCollection Documents/procesreglement-de-spreekuurrechter.pdf.

14. T. Lennaerts, 'De proef (met een) Spreekuurrechter', NJB 2017/2139, p. 2942.

15. Procesreglement Spreekuurrechter, onder 10, www.rechtspraak.nl/ SiteCollectionDocuments/procesreglement-de-spreekuurrechter.pdf); brochure Regelrechter, www.rechtspraak.nl/SiteCollectionDocuments/ folder-rotterdamse-regelrechter.pdf).

16. Luiten 2018, p. 138.

17. Regelrechter: onder 8, Procesreglement, www.rechtspraak.nl/Site CollectionDocuments/procesreglement-van-de-rotterdamse-regelrechter. pdf; Spreekuurrechter: onder 3, Procesreglement, www.rechtspraak.nl/ SiteCollectionDocuments/procesreglement-de-spreekuurrechter.pdf; Luiten 2018, p. 138.

18. Wetzels 2019a, p. 10; Lennaerts 2016, p. 806; Pijnappels 2019, p. 10; Luiten 2018, p. 138 (proces)recht en die kennis moeilijk kunnen verwerven, (beter) in staat te stellen hun recht te halen. Dit is opmerkelijk, omdat in de experimenten niet eerst is geconcludeerd dat de toegang tot de rechter voor bedrijven óók een probleem is, laat staan een probleem waarvoor de experimenten een oplossing moeten bieden. Ten tweede valt op dat de experimenten zich niet uitstrekken tot alle zaken, maar zich beperken tot verse, kleine en eenvoudige zaken (en bij de Wijkrechter nog tot een bepaalde categorie van zaken). De focus met betrekking tot het type zaken wordt zo beperkt, terwijl in het oogmerk van de experimenten daarvoor geen grond is te vinden. De experimenten zijn dus ruimhartig als het gaat om de doelgroep, maar zuinig als het gaat om het type zaken. Dat laatste roept de vraag op of partijen niet ook belang hebben bij een snelle, goedkope, laagdrempelige, eenvoudige en probleemoplossende procedure in zaken die groter en minder eenvoudig zijn of al langer tussen partijen spelen. De beperking lijkt met name ingegeven door de verwachting dat alleen in een beperkte groep van zaken de doelstellingen kunnen worden behaald.

Door de Spreekuurrechter zijn in de periode van $1 \mathrm{mei}$ 2016 tot 1 mei 2018160 aanmeldingen ontvangen. Daarvan zijn er 64 door de Spreekuurrechter behandeld, hoofdzakelijk doordat in de andere gevallen niet de medewerking van beide partijen kon worden verkregen. ${ }^{19}$ Door de Regelrechter zijn in de periode vanaf 15 september 2018 tot begin januari 2019 33 aanmeldingen ontvangen, waarvan 2 niet geschikt werden geacht voor de experimentele behandeling, in 8 zaken de wederpartij niet wilde meewerken en in 7 zaken nog niet duidelijk was of de wederpartij wilde meewerken. ${ }^{20}$ Een obstakel vormt het feit dat beide partijen moeten instemmen met behandeling van de zaak in het kader van het experiment. De Overlegrechter gaat er (mede om die reden) vooralsnog van uit om vanaf 1 juli 2019 in anderhalf jaar 50 zaken te behandelen. Voor experimenten die op termijn onder de nieuwe Experimenteerwet worden ingevoerd, is de instemming van beide partijen geen vereiste.

\section{Kwaliteit}

Alvorens op de onderscheiden aspecten van het oogmerk van de experimenten nader in te gaan, wordt in deze paragraaf besproken hoe het oogmerk van de experimenten zich verhoudt tot de kwaliteit van de civiele procedure. Daarvoor is nodig eerst stil te staan bij de vraag wat kwaliteit van de civiele procedure behelst.

Uit onderzoek volgt dat de kwaliteit van het civiele proces zich laat afmeten aan de mate waarin het proces toegankelijk, openbaar en eerlijk is en binnen een redelijke termijn partijen van een oordeel voorziet, waarbij partijen gehoord worden en geborgd wordt dat zij gelijke wapenen in handen hebben, onder leiding van een rechter die onafhankelijk, onpartijdig en deskundig is, de feiten zo veel mogelijk op de waarheid baseert

19. Hertogh e.a. 2018 , p. 8 -9.

20. Wetzels 2019b, p. 49. 
en zijn beslissing voorziet van een draagkrachtige motivering. ${ }^{21}$ Het is zaak voorstellen tot verbetering - zoals experimenten - af te zetten tegen de integrale kwaliteit van de civiele procedure. Daarmee wordt bedoeld kwaliteit in haar totaliteit, met oog voor alle verschillende aspecten waaruit deze totale kwaliteit is opgebouwd. Alleen op die manier kan inzicht worden verkregen of verbetering op één kwaliteitsaspect ook gevolgen heeft voor andere aspecten van kwaliteit, en daarmee of de integrale kwaliteit erop vooruitgaat.

Met de focus op snelheid richten de experimenten zich op het kwaliteitsaspect van tijdigheid. Met de focus op lage kosten en laagdrempeligheid/eenvoud richten de experimenten zich op het kwaliteitsaspect van toegankelijkheid. Daarbij gaat het zowel om een gemakkelijke entree tot de procedure (zonder bijvoorbeeld financiële barrières) als om een laagdrempelige, eenvoudige, duidelijke, klantgerichte en niet (te) formele procedure zelf. ${ }^{22}$

De focus op probleemoplossing laat zich niet goed onder een van de hiervoor genoemde kwaliteitsaspecten scharen. Wellicht past het nog het beste bij deskundigheid, tenminste voor wie probleemoplossing als taak van de rechter beschouwt (zie hierna par. 7).

De kwaliteitsaspecten van eerlijke behandeling, motivering van beslissingen, openbaarheid, waarheidsvinding, onafhankelijkheid en onpartijdigheid en deskundigheid van de rechter liggen buiten de focus van de verschillende experimenten. Op de meeste van die aspecten mogen de experimenten worden geacht geen invloed te hebben; er verandert niets aan de openbaarheid van de zitting, de motivering van de uitspraak, de deskundigheid en de onafhankelijkheid en onpartijdigheid van de rechter. Dat ligt mogelijk anders voor de aspecten waarheidsvinding en een eerlijke behandeling. Onder art. $96 \mathrm{Rv}$ bepaalt de rechter de procesvoering en bij de Spreekuurrechter wordt ook met zoveel woorden genoemd dat de rechter van de reguliere regels van burgerlijke rechtsvordering kan afwijken en 'niet alle stappen van dagvaarding, incidenten en conclusies' hoeft te doorlopen. ${ }^{23} \mathrm{Bij}$ de experimenten wordt in zijn algemeenheid alleen genoemd dat een stukkenwisseling in beginsel niet nodig is. Andere afwijkingen van het procesrecht zijn in de diverse procesreglementen niet benoemd. Het uitblijven van een stukkenwisseling op zich kan betekenen dat de feiten minder goed voor het voetlicht komen, zij het dat de zitting kan dienen om de feiten boven tafel te krijgen. Ook hoor en wederhoor kan in de knel komen zonder stukkenwisseling, zodat ook dat ter zitting (meer nog dan anders) aandacht behoeft. De gerechten hebben ruimte om te beoordelen of een zaak zich leent voor behandeling in het kader van het experiment. Aan de hand van welke criteria die beoordeling plaatsvindt, is niet steeds op voorhand duidelijk, wat mogelijk op gespannen voet staat met de rechtszekerheid. Daarnaast

21. K.G.F. van der Kraats, De eigen(aardig)heid van de kantonrechter, Den Haag: Boom juridisch 2017, p. 163; Asser Procesrecht/Giesen 1 2015; R.H. de Bock, Tussen waarheid en onzekerheid (diss. Tilburg), Deventer: Kluwer 2011; W.M. Rutten-van Deurzen, Kwaliteit van rechtspleging (diss. Tilburg), Nijmegen: Wolf Legal Publishers 2010.

22. Van der Kraats 2017, p. 152-153.

23. Lennaerts 2016, p. 805 . komen de rechtseenheid en de rechtsgelijkheid onder druk te staan, nu niet alle zaken kunnen worden aangebracht en regionaal verschillen bestaan tussen gerechten (wel of geen experiment en de verschillen tussen de verschillende experimenten) in de wijze waarop - en als we het oogmerk van de experimenten aannemen ook in de mate waarin - mensen hun recht kunnen halen. Wanneer het gaat om verschillen met als doel kleinschalig te kunnen uitproberen welke experimenten zich lenen voor landelijke invoering, zijn deze wellicht onvermijdbaar en vallen deze gedurende een korte periode te billijken.

Als in de navolgende paragrafen wordt stilgestaan bij snelheid, kosten, laagdrempeligheid/eenvoud en probleemoplossing van de experimentele procedures zal dan ook met name worden gekeken naar de waarde daarvan voor de kwaliteitsaspecten van tijdigheid en toegankelijkheid en de risico's daarvan voor de waarheidsvinding en het recht op een eerlijk proces.

\section{Snel}

De experimenten beogen de procedure sneller te laten verlopen en daarmee bij te dragen aan het kwaliteitsaspect van tijdigheid. Die snelheid wordt op verschillende wijzen behaald. Er wordt niet gewacht op betaling van het griffierecht (door toepassing te geven aan de hardheidsclausule van art. 127a lid $3 \mathrm{Rv}),{ }^{24}$ de mondelinge behandeling wordt snel na de aanmelding gepland, en de uitspraak vindt daarna snel plaats.

Op grond van art. 127a lid $1 \mathrm{Rv}$ houdt de rechter de zaak aan zolang de eisende partij het griffierecht niet heeft voldaan. De termijn hiervoor is ingevolge art. 3 lid 3 van de Wet griffierechten burgerlijke zaken (Wgbz) vier weken. In het derde lid van art. 127a Rv, de hardheidsclausule, is bepaald dat de rechter niet hoeft te wachten tot het griffierecht betaald is, indien hij van oordeel is dat dat, gelet op het belang van één of meer van de partijen bij toegang tot de rechter, zal leiden tot een onbillijkheid van overwegende aard. Het is evident dat snelheid kan worden behaald door niet te wachten op betaling van het griffierecht. Kennelijk wordt gemeend dat de toegang tot het experiment in algemene zin een dergelijke uitzondering rechtvaardigt. Het valt te betwijfelen of een dergelijke algemene uitzondering verenigbaar is met de ratio van een hardheidsclausule, die in beginsel noopt tot een individuele, zaaksgerichte afweging. Daarenboven kan dit op gespannen voet komen te staan met de rechtsgelijkheid. Ik kan immers geen goede reden - en die reden wordt in het kader van de experimenten ook niet gegeven - bedenken waarom in het kader van de experimenten het belang van betaling van het griffierecht moet wijken voor het belang van tijdigheid en in alle andere zaken niet.

In alle experimentele zaken wordt een zitting gepland. De termijn waarbinnen een zitting wordt gepland, is niet hard omschreven. Bij de Spreekuurrechter zou dat gemiddeld binnen drie weken zijn geweest. ${ }^{25}$ Als de zitting niet uitmondt in een schikking tussen partijen, doet de rechter ook in de experimenten uitspraak. De termijn voor het doen van uit-

24. Wetzels 2019b, p. 45.

25. Lennaerts 2017, p. 2939. 
spraak is bij de Regelrechter binnen twee weken na de zitting en bij de Wijkrechter binnen vier weken na de zitting. ${ }^{26}$

Juist de snelheid van de procedure bleek bij de Spreekuurrechter voor veel mensen een reden om voor deelname aan het experiment te kiezen. ${ }^{27}$ Natuurlijk wordt een tijdige beslechting van het geschil makkelijker wanneer korte, harde termijnen worden gehanteerd voor het plannen van een zitting en het doen van een uitspraak. Dat geldt evenwel niet alleen voor de experimentele zaken, maar voor alle zaken. Waarom kan dat dan in experimentele zaken wel en in andere niet? Zowel bij de Spreekuurrechter als bij de Regelrechter blijkt dat de zaken in het kader van het experiment voorrang krijgen boven andere zaken. ${ }^{28}$ Kortom, andere zaken moeten langer wachten om de experimentele zaken eerder te kunnen behandelen. Dit creëert rechtsongelijkheid, want waarom is snelheid in de experimentele zaken belangrijker dan in andere zaken? Het zorgt er ook voor dat je in het kader van een evaluatie moeilijk zal kunnen onderscheiden of de vernieuwing nu voor eventuele versnelling verantwoordelijk is, of het gevolg is van het feit dat de zaken in het experiment voorrang hebben gekregen boven reguliere zaken.

\section{Goedkoop}

De experimenten houden een procedure tegen lagere kosten in. Partijen hoeven geen dagvaardingskosten te maken, partijen hoeven zich niet te laten bijstaan door een advocaat of een andere gemachtigde, en als een van partijen een natuurlijke persoon is, wordt - ongeacht het financiële belang van de zaak - (behoudens bij de Spreekuurrechter) het laagste griffierecht in rekening gebracht ( $€ 81$ ). Deze drie punten waarin bij experimentele zaken kosten kunnen worden bespaard, zal ik hierna achtereenvolgens bespreken. Het uitsparen van de dagvaardingskosten is eigen aan een procedure op basis van art. $96 \mathrm{Rv}$ en een financieel voordeel voor partijen. Hierbij dient evenwel te worden opgemerkt dat ook in een reguliere dagvaardingsprocedure partijen kunnen afspreken dat gedaagde vrijwillig zal verschijnen, zodat dagvaardingskosten kunnen worden uitgespaard. Bij mijn weten gebeurt dit echter niet vaak. Ook in reguliere kantonzaken hoeven partijen zich niet te laten bijstaan door een advocaat of andere gemachtigde. Dat dit in experimentele zaken niet hoeft, levert dus alleen een financieel voordeel op in handelszaken. De vraag is of handelszaken zich wel lenen voor behandeling in het kader van het experiment (dat immers is voorbehouden aan eenvoudige zaken) en voor behandeling zonder een advocaat. Uitgangspunt van de wetgever is dat dat niet het geval is, maar partijen kunnen daar op basis van art. $96 \mathrm{Rv}$ van afwijken. De vraag is echter of de doelgroep waarop de experimenten zich richten een dergelijke keuze wel goed kan overzien. Niet ondenkbaar is dat het voordeel van een snelle en goedkope procedure bij aanvang zo zwaar weegt dat het risico van het ontbreken van juridische bijstand voor lief wordt genomen. Het is aan de behandelend rechter om als gamekeeper hiervoor

26. Wetzels 2019b, p. 48; Luiten 2018, p. 139.

27. Lennaerts 2017, p. 2940.

28. Hertogh e.a. 2018, p. 40; Wetzels 2019b, p. 49 te waken en mogelijk de zaak dan niet geschikt te achten voor de experimentele behandeling. Als de rechter die rol vervult, wordt het financiële voordeel van het niet hoeven inschakelen van een advocaat of gemachtigde ten opzichte van de zaken waarin dit normaliter wel moet, waarschijnlijk slechts in een zeer beperkt aantal zaken gerealiseerd.

Voor het lagere griffierecht wanneer ten minste één partij een natuurlijke persoon is, is gekozen 'omdat de pilot beoogt een laagdrempelige procedure te bieden voor de particulier. ${ }^{29}$ Het beperken van het griffierecht in zaken met een natuurlijke persoon kent naar mijn idee twee bezwaren. Ten eerste het bezwaar van de rechtsongelijkheid; waarom alleen bij betrokkenheid van natuurlijke personen? En waarom alleen in bepaalde zaken? Het antwoord op de eerste vraag luidt waarschijnlijk dat de Rechtspraak - zoals eerder ook geuit - meent dat het griffierecht juist in de kleinste zaken te hoog is. ${ }^{30}$ En daarmee kom ik op mijn tweede bezwaar; het vaststellen van het griffierecht is voorbehouden aan de minister, en op grond van de Wgbz moet in beginsel ook in het kader van art. $96 \mathrm{Rv}$ een griffierecht worden geheven gelijk aan dat in de reguliere procedure. De Wgbz biedt geen grondslag voor een lager griffierecht in het kader van art. $96 \mathrm{Rv}$.

Voorts wordt bij de Regelrechter en de Overlegrechter nog opgemerkt dat iedere partij in beginsel de eigen kosten draagt, tenzij uitdrukkelijk om een kostenveroordeling is gevraagd. ${ }^{31}$ Voor de verliezende partij is dat dan goedkoper dan in een reguliere procedure, maar voor de winnende partij niet. Het lijkt mij niet rechtvaardig dat de winnende partij mogelijk duurder uit is. Niet uitgesloten is weliswaar dat partijen ook in het kader van een experiment een kostenveroordeling verzoeken, maar als de rechter die optie niet nadrukkelijk benoemt, is het de vraag of een natuurlijke persoon hier uit zichzelf aan denkt, en hoe dit zich verhoudt tot een eerlijk proces. De rechter zou partijen hier mijns inziens wel op moeten wijzen.

\section{Laagdrempelig en eenvoudig ${ }^{32}$}

Het lagere griffierecht (dat bij de Regelrechter, de Wijkrechter en de Overlegrechter wordt geheven) draagt bij aan de toegankelijkheid. Daarnaast wordt de procedure in het kader van de experimenten eenvoudiger (en daarmee mogelijk laagdrempeliger en toegankelijker) doordat de procedure niet hoeft te worden ingeleid met een schriftelijk stuk (zoals een dagvaarding of een verzoekschrift), maar kan worden volstaan met het invullen van het aanmeldformulier, waarbij in enkele regels het geschil wordt omschreven en dat desgewenst kan worden

29. Wetzels 2019b, p. 44.

30. Er zijn voldoende aanwijzingen dat de hoogte van het griffierecht met name in zaken met een kleiner financieel belang daadwerkelijk een drempel opwerpt. Denk alleen al aan de terugloop in het aantal zaken met een financieel belang onder $€ 5000$ en het succes van bijv. e-Court.

31. Wetzels 2019a, p. 9; 2019b, p. 45.

32. Dit zijn twee verschillende begrippen; eenvoud draagt bij aan toegankelijkheid, toegankelijkheid is meeromvattend dan eenvoud. Omdat zij in het kader van de experimenten vaak in één adem worden genoemd, behandel ik ze hier gezamenlijk in één paragraaf. 
verstuurd per e-mail. ${ }^{33}$ Een uitwisseling van processtukken is in ieder geval tot de zitting niet nodig. ${ }^{34}$ Dit maakt de procedure waarschijnlijk eenvoudiger (althans in aanvang) en haalt mogelijk een barrière weg om een rechtszaak te beginnen. Hieraan draagt mogelijk ook bij dat partijen zich niet noodzakelijk hoeven te laten bijstaan door een advocaat of andere gemachtigde (zie par. 5). De vraag is echter wel of hieraan geen negatieve gevolgen voor de waarheidsvinding en het ordelijk verloop van de procedure kleven. Het risico bestaat immers dat zonder schriftelijke stukken (waarin gedachten logisch geordend zijn en die men heeft kunnen lezen en herlezen) en een advocaat of gemachtigde om zijn cliënt en de rechter te helpen de relevante feiten te benoemen en uit het verhaal te destilleren, juridisch relevante feiten onbenoemd of versluierd blijven. Een criticaster zou wellicht hiertegenover kunnen stellen dat juist advocaten en gemachtigden ervoor zorgen dat relevante of werkelijke (onwelgevallige) feiten onder tafel blijven, maar daarmee zou vele advocaten en gemachtigden onrecht worden gedaan. De rechter zal in het kader van de experimenten nog meer dan gebruikelijk de belangrijke taak hebben om ervoor te zorgen dat alle relevante feiten boven tafel komen. Dat vereist - meer nog dan in andere zaken - een actieve en onderzoekende rechter die ad hoc in staat is om het verhaal van partijen in een juridisch kader te plaatsen en vanuit dat juridisch kader de juiste vragen te stellen om een juist oordeel te kunnen vellen.

In paragraaf 3 is al angehaald dat in het kader van art. 96 Rv de rechter de procesvoering bepaalt en daarbij kan afwijken van het reguliere procesrecht. Het wordt in het kader van de experimenten als voordeel benoemd dat partijen daarbij 'maximaal invloed' kunnen uitoefenen op het procesverloop. ${ }^{35}$ Daarbij zal de rechter wel toezicht moeten houden op de eerlijkheid van de procedure (gelijkheid der wapenen) en de waarheidsvinding. Zo staat in het kader van art. $96 \mathrm{Rv}$ in beginsel geen hoger beroep open, tenzij partijen zich vooraf dit recht hebben voorbehouden (art. $333 \mathrm{Rv}$ ). In het aanmeldformulier voor de Regelrechter en de Overlegrechter wordt partijen gevraagd aan te geven of zij zich de mogelijkheid van hoger beroep willen voorbehouden. Het is maar zeer de vraag of particulieren zonder gemachtigde - de primaire doelgroep van de experimenten - in staat zijn die keuze te overzien. Om dat zeker te stellen zal de rechter daarnaar ter zitting nog eens uitdrukkelijk moeten vragen.

De Wijkrechter neemt (standaard) zitting in de wijk. ${ }^{36}$ Daarmee kan de procedure toegankelijker zijn dan de reguliere procedure (want de rechter is meer nabij) en beter toegankelijk voor potentiële bezoekers dan een gerecht dat zich op afstand bevindt.

\section{Probleemoplossend}

In paragraaf 3 is reeds stilgestaan bij het feit dat 'probleemoplossing' - waar de experimenten op focussen - niet (eenvou-

33. Wetzels 2019a, p. 10; Luiten 2018, p. 138.

34. Wetzels 2019 a, p. 10

35. Lennaerts 2016, p. 805; Wetzels 2019a, p. 11.

36. Luiten 2018, p. 138. dig) binnen de gegeven kwaliteitsdefinitie kan worden gebracht. Tijdens reguliere zittingen stelt de rechter partijen in beginsel de vraag of zij nog een minnelijke regeling willen beproeven. Wanneer partijen daaraan behoefte hebben, kan de rechter daarbij behulpzaam zijn door een voorlopig oordeel te geven of met partijen mogelijke oplossingsrichtingen te bespreken. Dit is inmiddels common practice, maar in de experimenten gaat de rechter verder. Zo zal de Regelrechter naar verluidt 'meer nog dan in een reguliere dagvaardingsprocedure, tijdens de zitting met partijen het gesprek (...) aangaan om te bezien of het geschil in der minne en in goed overleg tussen partijen tot een oplossing kan worden gebracht'. ${ }^{37}$ Daarbij maakt de rechter gebruik van 'mediationachtige technieken' 'om zodoende het geschil definitief te beslechten' ${ }^{38}$ Bij de Spreekuurrechter wordt bezien 'of volstaan kan worden met bemiddeling en/of advies/mening. ${ }^{39}$ In het kader van het experiment geeft de rechter dus zelfs een (particuliere?) mening of advies. Ook de Regelrechter geeft zo nodig advies. ${ }^{40}$

De Wijkrechter koppelt daaraan dat hij 'niet enkel een beslissing [wil] nemen over het voorgelegde geschil, maar [wil] zorgen dat rechtzoekenden, instanties en andere partijen weer samen door één deur kunnen'. ${ }^{41}$

Recent - na eerder ook De Bock ${ }^{42}$ en Coenraad en Ingel$\mathrm{se}^{43}$ - heeft Ahsmann vraagtekens gezet bij de rechter als geschiloplosser in plaats van geschilbeslechter en vraagt zich af hoe in die rol de fundamentele beginselen van procesrecht worden geborgd. ${ }^{44}$ Vranken en Snel hebben er recent op gewezen dat de verwachting van een probleemoplossende rechter nimmer kan worden waargemaakt, en dat elke suggestie dat een civiele overheidsrechter het onderliggende probleem oplost, verkeerd is. ${ }^{45}$ Volgens hen is het voor de civiele overheidsrechter onmogelijk om tegelijk problem solver te zijn vanwege de gebondenheid aan het materiële recht en aan fundamentele beginselen van procesrecht. $\mathrm{Zij}$ vinden het verlangen van probleemoplossing door de civiele rechter getuigen van gevaarlijke arrogantie. ${ }^{46}$

Maar in de experimenten worden nog hogere doelen gesteld. Zo wil de Wijkrechter de leefbaarheid in de wijken bevorderen. ${ }^{47}$ Hoe dan? Kan een rechter dat? Behoort dat tot de rechterlijke taak? De Spreekuurrechter richt zich er zelfs op

37. Wetzels 2019 b, p. 46 .

38. Wetzels 2019a, p. 10; 2019b, p. 42 en 48.

39. Lennaerts 2016, p. 807.

40. Brochure, www.rechtspraak.nl/SiteCollectionDocuments/folder-rotter damse-regelrechter.pdf.

41. Pijnappels 2019, p. 10.

42. R.H. de Bock, 'Grip op kwaliteit', in: Kwaliteit als keuze: kwaliteit(sbeoordeling) van rechtspraak, wetgeving en rechtswetenschappelijk onderzoek (Handelingen Nederlandse Juristen-Vereniging 2015-1), Deventer: Wolters Kluwer 2015, nrs. 26 e.v.

43. L. Coenraad \& P. Ingelse, 'Afscheid van de klassieke civiele procedure?', in: Afscheid van de klassieke procedure (Handelingen Nederlandse Juristen-Vereniging 2017-1), Deventer: Wolters Kluwer 2017, par. 3.4.

44. M.J.A.M. Ahsmann, Samenwerking Rechtswetenschap en Rechtspraak: van nut naar noodzaak! (Afscheidsrede Leiden), 2019, p. 9.

45. J. Vranken \& M. Snel, 'De civiele rechter in Nederland op de schopstoel', NJB 2019/687, p. 858 en 865.

46. Vranken \& Snel 2019, p. 865.

47. Luiten 2018, p. 138. 
'de intrinsieke redelijkheid van recht en rechtspraak dichter bij de rechtsgenoten' te brengen. ${ }^{48}$ Wat betekent dit? Hoe kan een rechter dat? Het lijken mij verwachtingen die onmogelijk kunnen worden gerealiseerd, een recept voor teleurstelling. Dat is jammer, want het leidt af van de verbetering die met de experimenten mogelijk wel kan worden bereikt.

\section{Conclusie}

Experimenten die beogen de kwaliteit van de civiele procedure te verbeteren en oplossingen te vinden voor problemen die rechtszoekenden ervaren in het halen van hun recht, verdienen in dat streven waardering. En wie nooit iets nieuws probeert, zal zeker niet slagen in het bereiken van verbetering.

De experimenten beogen een snelle, goedkope, laagdrempelige/eenvoudige procedure te bieden, die problemen daadwerkelijk oplost. Daarmee pogen ze met name de tijdigheid en toegankelijkheid van de civiele procedure te bevorderen. Er kleven echter ook risico's aan op de kwaliteitsaspecten van waarheidsvinding en een eerlijk proces (met name rechtsgelijkheid).

Op dat laatste aspect is van invloed dat de experimenten slechts bij enkele gerechten lopen en onderling van elkaar verschillen. Niet overal heeft iedere potentiële partij dus dezelfde opties. Daarbij komt dat slechts een beperkt aantal zaken kan worden aangebracht (enigszins verschillend per experiment), waarbij de rechter aan de hand van op voorhand niet volledig duidelijke criteria alsnog kan besluiten dat de zaak zich niet leent voor de experimentele behandeling. Om het risico op rechtsongelijkheid en rechtsonzekerheid dat dit met zich brengt te beperken, zullen de experimenten in tijd beperkt moeten zijn (maar wel voldoende om te kunnen onderzoeken of het een succes is), zal de rechter ruimhartig moeten zijn in het accepteren van zaken in het kader van het experiment, en duidelijk moeten motiveren waarom een zaak eventueel niet geschikt is.

Bij de zaken die binnen het experiment vallen, hoeft niet eerst het griffierecht te zijn voldaan (op basis van de hardheidsclausule van art. 127a lid $3 \mathrm{Rv}$ ), hoeft minder griffierecht betaald te worden als een van de partijen een particulier is, en worden op kortere termijn zittingen gepland en uitspraken gedaan ten koste van reguliere zaken. Zo bezien worden partijen met experimentele zaken bevoordeeld ten opzichte van partijen in reguliere zaken. Je kunt je dan afvragen hoe vrij de keuze van partijen nog is om deel te nemen aan de pilot, voor die zaken waarin dat überhaupt een optie is. Bovendien is het zeer de vraag of de bevoordeling in experimentele zaken op het punt van het categorisch toepassen van de hardheidsclausule bij betaling van het griffierecht en het heffen van een lager griffierecht wanneer ten minste één van partijen particulier is, wettelijk wel is toegestaan.

De waarheidsvinding kan onder druk komen te staan doordat er geen schriftelijke stukkenuitwisseling en geen advocaat of gemachtigde vereist zijn. Het is aan de rechter om te voorkomen dat dit risico zich realiseert.
Deze risico's tonen aan hoe belangrijk het is om wijzigingen in het procesrecht gepaard te laten gaan van een integrale kwaliteitstoets. Wanneer op slechts één kwaliteitsaspect wordt gefocust, kan de rest buiten beeld raken en kan winst op één aspect van kwaliteit verlies op een ander aspect betekenen.

Experimenten zijn belangrijk om tot verbetering van het civiele proces te komen, om te kunnen zien wat wel en wat niet werkt. Belangrijk is daarbij om een duidelijk kader te hebben waaraan kan worden getoetst, zowel vooraf (bij formulering van de hypothese dat het beoogde experiment zal bijdragen aan het beoogde doel) als achteraf (bij het bepalen of de hypothese is bewezen of niet). Dat kader biedt de in paragraaf 3 gedefinieerde integrale kwaliteit. Voorts is van belang om de rol en taak van de rechter (en de beperkingen die daarbij horen) scherp voor ogen te hebben en niet op voorhand teleurstelling te creëren door onrealistische verwachtingen te scheppen, zoals een probleemoplossende rechter die de leefbaarheid in de wijken bevordert of zelfs 'de intrinsieke redelijkheid van recht en rechtspraak dichter bij de rechtsgenoten' brengt.

48. Lennaerts 2016, p. 808. 